\title{
A tumor-derived population (SCCOHT-1) as cellular model for a small cell ovarian carcinoma of the hypercalcemic type
}

\author{
ANNA OTTE ${ }^{1}$, GUDRUN GÖHRING ${ }^{2}$, DORIS STEINEMANN ${ }^{2}$, BRIGITTE SCHLEGELBERGER ${ }^{2}$, \\ STEPHANIE GROOS $^{3}$, FLORIAN LÄNGER ${ }^{4}$, HANS-HEINRICH KREIPE ${ }^{4}$, AXEL SCHAMBACH $^{5}$, \\ THOMAS NEUMANN $^{5}$, PETER HILLEMANNS ${ }^{1}$, TJOUNG-WON PARK-SIMON ${ }^{1}$ and RALF HASS ${ }^{1}$ \\ ${ }^{1}$ Department of Obstetrics and Gynecology, ${ }^{2}$ Institute of Cell and Molecular Pathology, ${ }^{3}$ Institute of Cell Biology, \\ ${ }^{4}$ Institute of Pathology, ${ }^{5}$ Department of Experimental Hematology, Medical University, Hannover, Germany
}

Received January 12, 2012; Accepted March 16, 2012

DOI: $10.3892 /$ ijo.2012.1468

\begin{abstract}
The small cell ovarian carcinoma of the hypercalcemic type (SCCOHT) represents an aggressive tumor with poor prognosis predominantly affecting young women and so far, no cell line or animal model is available to investigate this devastating disease. Biopsy material from a recurrent SCCOHT was subjected to an explant culture to obtain an adherent and continuously proliferating cell population. Morphological and functional characterization revealed a heterogeneous population (SCCOHT-1) of about $13 \mu \mathrm{m}$ in diameter and approximately $36 \mathrm{~h}$ of doubling time. Flow cytometric analysis of surface markers demonstrated the expression of CD15, CD29, CD44 and CD90 paralleled by the presence of cytokeratins and vimentin. Cytogenetic analysis and high-resolution oligo-array comparative genomic hybridization $(\mathrm{aCGH})$ demonstrated a stable karyotype including deletions of the PARK2, CSMD1, GRIN2B and ATF7IP genes. Following lentiviral transduction with a GFP vector, the labeled SCCOHT-derived cells were subjected to CCE to separate distinct subpopulations as evidenced by cell cycle analysis. Subcutaneous injection of these subpopulations into NOD/SCID mice exhibited hypercalcemia and a tumor development in $100 \%$ of the mice. Re-cultivation of the mouse tumors revealed an outgrowth of SCCOHT-derived phenotypes and all cell populations expressed high telomerase activity. Moreover, histopathological evaluation demonstrated close similarities between the mouse tumors and the original patient tumor. In conclusion, SCCOHT-1 cells provide a study platform to investigate this rare disease and to examine effective and sufficient therapeutic strategies for this rather unknown type of cancer.
\end{abstract}

Correspondence to: Dr Ralf Hass, Biochemistry and Tumor Biology Laboratory, Gynecology Research Unit, Department of Obstetrics and Gynecology, Medical University Hannover, 1 Carl Neuberg Str., D-30625 Hannover, Germany

E-mail: hass.ralf@mh-hannover.de

Key words: small cell ovarian carcinoma of the hypercalcemic type, ovarian cancer, tumor growth, chromosomal aberration, cell cycle

\section{Introduction}

The small cell ovarian carcinoma of the hypercalcemic type (SCCOHT) is defined as a rare form of an aggressive ovarian tumor predominantly affecting young women between ages of 13 to 35 which is mostly associated with paraendocrine hypercalcemia $(1,2)$. Following the initial histopathological evaluation of several clinical cases, the SCCOHT has been classified as a separate pathological entity (3).

This malignancy with poor prognosis has been described to be different and clearly distinguishable from other related cancer types including transitional cell carcinoma of the ovary, ovarian epithelial tumors and ovarian germ cell tumors $(3,4)$. A variety of cell lines are available to study different types of ovarian carcinoma including BG-1 (5), NIH:OVCAR-3 (6), OTN11 (7) and Ov202 (8), however, no cellular model so far exhibits properties of an SCCOHT. A previous cell line (OS-1) described to be associated with an ovarian small cell carcinoma of the hypercalcemic type failed to develop tumors in immunodeficient nude mice (9). Therefore, no cell system associated with an appropriate SCCOHT in vivo model is available up to now.

Based upon initial immunohistochemical analysis the SCCOHT has been postulated to represent a germ cell-derived tumor (10). Other evaluations including electron microscopy of tumor specimen reported SCCOHT as an epithelial-like originating tumor (2). However, further investigations using immunohistochemistry, electron microscopy and genetic analysis of SCCOHT tumor specimen suggested a heterogeneous tumor entity not confirming a germ cell-derived or an epithelial cell-derived tumor origin (11-13). Considering these controversial reports, the histogenesis of SCCOHT and the mechanism of the development of the hypercalcemia still remain unclear.

Properties of the SCCOHT appear to be heterogeneous and no defined markers for the characterization of these tumor cells have been identified. Morphological evaluations of the cells in SCCOHT tumor biopsies described irregularly clumped nuclear chromatin with small detectable nucleoli (14). Moreover, some populations stained positive for epithelial cell markers whereas the intermediate filament protein vimentin has been described in the majority of cells in the SCCOHT (11). In addition, cell cycle analysis of several SCCOHT tumors by flow cytometry 
reported a broad distribution with $4.7 \%$ to $18 \%$ of S phase cells and $1.5 \%$ to $19.5 \%$ of $\mathrm{G}_{2} / \mathrm{M}$ phase cells (15).

The heterogeneity of these data may be explainable in part due to the limitations of the biopsy material from patients and the lack of further cell sources, whereby the histogenesis and properties of the SCCOHT still remain poorly understood. Consequently, reasonable approaches for the treatment of SCCOHT patients or a sufficient (chemo) therapeutic management remain unknown. So far, a multimodality treatment is suggested which includes surgery followed by a cisplatin- and etoposide-based or carboplatin- and taxane-based chemotherapy and the addition of a sequential or concurrent radiotherapy $(16,17)$ although the level of tumor relapses remains high. Thus, more than $70 \%$ of the SCCOHT patients who had received a tumor-reductive surgery and subsequent chemotherapy rapidly developed a tumor relapse and only very few patients survived longer than two years (18-21). Current recommendations also include the administration of high dose chemotherapy which may yield longer term remissions (22).

In the present study, we describe a permanently growing and transplantable SCCOHT-derived cell population representing a model for appropriate in vitro and in vivo tumor studies which may contribute to a more detailed understanding of this devastating disease.

\section{Materials and methods}

Patient biopsy and primary culture of SCCOHT-derived cells. A 31-year-old woman was diagnosed clinically and histopathologically with an ovarian small-cell carcinoma of the hypercalcemic type, FIGO Ia. The German Gynecopathologic Reference Laboratory in Mannheim confirmed the diagnosis of this rare tumor. The patient was primarily treated by oophorectomy and refused chemotherapy secondary to desired pregnancy. Only 11 months later she presented with hypercalcemia $(2.87 \mathrm{mmol} / \mathrm{l}$, normal less than $2.60 \mathrm{mmol} / \mathrm{l}$ ) and recurrent pelvic mass. An exploratory laparotomy was performed and revealed large intraabdominal tumor masses. The patient died 13 months after primary diagnosis. The final diagnosis rendered was recurrent small cell carcinoma of the hypercalcemic type.

During surgery of this 31-year-old patient with recurrent SCCOHT a tumor biopsy was taken and washed several times in PBS supplemented with $100 \mathrm{U} / \mathrm{ml}$ penicillin and $100 \mu \mathrm{g} / \mathrm{ml}$ streptomycin. Informed written consent was obtained from the patient for the use of this biopsy material and the study has been approved by the Institutional Review Board, Project no. 3916 on June 15th, 2005. Following removal of most erythrocytes, the tumor tissue was minced with a scalpel into approximately $2 \mathrm{~mm}^{3}$ large tissue pieces, washed again and incubated in growth medium with $400 \mu \mathrm{M}$ $\mathrm{Ca}^{2+}$, i.e. RPMI-1640 supplemented with $10 \%$ (v/v) fetal calf serum or human AB serum, $100 \mathrm{U} / \mathrm{ml} \mathrm{L-glutamine,} 100 \mathrm{U} / \mathrm{ml}$ penicillin and $100 \mu \mathrm{g} / \mathrm{ml}$ streptomycin. The tissue culture was performed at $37^{\circ} \mathrm{C}$ in a humidified atmosphere of $5 \%(\mathrm{v} / \mathrm{v}) \mathrm{CO}_{2}$ and the medium was changed at intervals of 3 to 4 days to remove remaining blood cells and small debris. Following the outgrowth of an adherent cell population, the tumor tissue pieces were removed and the adherent cell layer could be harvested by gentle scraping using a sterile rubber policeman to avoid the use of non-specific proteases such as trypsin. The cells were centrifuged (320 g/6 min) and resuspended in growth medium and this primary culture continued to grow without further purification or selection. The proliferative capacity at various conditions and the population doublings in parallel to the cell viability during culture were determined in a hemocytometer using the trypan blue exclusion test.

Scanning electron microscopy (SEM). Cells grown on coverslips were washed in PBS and immersed in a fixative solution composed of $2.5 \%$ glutaraldehyde, $2 \%$ formaldehyde, freshly prepared from paraformaldehyde, $1.7 \mathrm{mM} \mathrm{CaCl}$ and Na-Cacodylate- $\mathrm{HCl}$ buffer $\mathrm{pH} 7.3$ for at least $4 \mathrm{~h}$ at $4^{\circ} \mathrm{C}$.

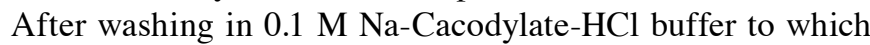
$0.22 \mathrm{M}$ sucrose was added the cells were postfixed in buffered $2 \% \mathrm{OsO}_{4}$, dehydrated in ascending concentrations of acetone and subsequently dried in a Balzers CPD 030 critical point dryer (Bal-Tec AG, Balzers, Liechtenstein). The coverslips were mounted on aluminium stubs with conductive plates (Plano, Wetzlar, Germany), sputter coated with gold in a Polaron E 5400 sputter coater (Polaron Equipment Ltd., Watford, UK) and investigated in a Philips SEM 505 scanning electron microscope at an acceleration voltage of $10 \mathrm{kV}$. Images were recorded using the SEM software version 2.0 (23).

Transmission electron microscopy (TEM). Cells grown in plastic Petri dishes with a diameter of $3.5 \mathrm{~cm}$ were fixed as described for SEM. After washing in $0.1 \mathrm{M} \mathrm{Na}-\mathrm{Cacodylate-} \mathrm{HCl}$ supplemented with $0.22 \mathrm{M}$ sucrose and post-fixation in $2 \%$ $\mathrm{Na}$-Cacodylate-buffered $\mathrm{OsO}_{4}$ for $90 \mathrm{~min}$ at room temperature, the cells were dehydrated in ascending concentrations of ethanol and finally embedded in epoxy resin (Serva, Heidelberg, Germany).

Thin sections (about $70 \mathrm{~nm}$ thick) were cut with an ultramicrotome Reichert Ultracut E, collected on formvar-coated copper slot grids, contrasted with uranylacetate and lead citrate and observed in a transmission electron microscope Morgagni 268 (FEI, Eindhoven, The Netherlands) at an acceleration voltage of $80 \mathrm{kV}$. Images were acquired using a Veleta CCD camera (Olympus SIS, Münster, Germany) controlled by iTEM software Version 5.1 (Olympus SIS).

Analysis of surface markers by flow cytometry. Continuously proliferating SCCOHT-derived cells in logarithmic growth phase were harvested and analysed for cell surface marker and intermediate filament expression. After blocking non-specific binding to Fc-receptors by incubation of $10^{6}$ SCCOHT-derived cells with human $\operatorname{IgG}(10 \mathrm{mg} / \mathrm{ml})$ for $30 \mathrm{~min}$ at $4^{\circ} \mathrm{C}$ and washing with PBS-BSA, the cells were incubated with the specific FITC- or PE-conjugated antibodies listed in Table I, respectively. A parallel incubation with the appropriately labeled IgG subclass antibody served as a control. Following antibody incubation, all samples were washed twice with PBS-BSA and flow cytometry was performed in a Galaxy FACScan (Partec $\mathrm{GmbH}$, Münster, Germany) using FloMax analysis software (Partec GmbH).

Centrifugal counterflow elutriation (CCE). The CCE was performed using the Beckmann J6-MC with the JE-5.0 rotor and the appropriate $5 \mathrm{ml}$-standard elutriation 
Table I. Surface markers and intermediate filaments in SCCOHT-1 cells.

\begin{tabular}{|c|c|c|c|c|}
\hline $\begin{array}{l}\text { Tested } \\
\text { antibody on } \\
\text { SCCOHT-1 }\end{array}$ & $\begin{array}{c}\mathrm{IgG} \\
\text { subclass }\end{array}$ & Labeling & Source & $\begin{array}{c}\text { SCCOHT-1 } \\
\text { signal }(\%)\end{array}$ \\
\hline CD11b & IgG1 & $\mathrm{PE}$ & DAKO & 0 \\
\hline CD15 & IgG1 & PE & Miltenyi & 15.6 \\
\hline $\mathrm{CD} 24$ & $\operatorname{IgG} 2 \mathrm{a}$ & FITC & BD Bioscience & 0 \\
\hline CD29 & IgG1 & PE & BD Bioscience & 77.4 \\
\hline CD31 & IgG1 & FITC & DAKO & 0 \\
\hline CD44 & $\operatorname{IgG} 2 \mathrm{a}$ & FITC & BD Bioscience & 8.3 \\
\hline CD45 & $\mathrm{IgG} 1$ & FITC & DAKO & 0 \\
\hline $\mathrm{CD} 49 \mathrm{~b}$ & IgG1 & FITC & BD Bioscience & 0 \\
\hline CD49d & IgG1 & PE & BD Bioscience & 0 \\
\hline CD49f & $\operatorname{IgG} 2 \mathrm{a}$ & FITC & BD Bioscience & 0 \\
\hline CD54 & $\operatorname{IgG} 2 b$ & PE & BD Bioscience & 0 \\
\hline CD66 & IgG1 & FITC & BD Bioscience & 0 \\
\hline CD73 & IgG1 & $\mathrm{PE}$ & BD Bioscience & 0 \\
\hline CD90 & IgG1 & PE & DAKO & 91.0 \\
\hline CD103 & $\operatorname{IgG} 2 \mathrm{a}$ & FITC & BD Bioscience & 0 \\
\hline CD105 & IgG1 & FITC & BioLegend & 0 \\
\hline CD133 & $\operatorname{IgG} 2 b$ & $\mathrm{PE}$ & Miltenyi & 0 \\
\hline CD138 & IgG1 & PE & BD Bioscience & 0 \\
\hline CD147 & IgG1 & PE & BD Bioscience & 0 \\
\hline CD227 & IgG1 & $\mathrm{PE}$ & BD Bioscience & 0 \\
\hline CD271 & IgG1 & PE & Miltenyi & 0 \\
\hline MSCA & IgG1 & $\mathrm{PE}$ & Miltenyi & 0 \\
\hline Pan cytokeratin & IgG1 & FITC & DAKO & 28.0 \\
\hline Vimentin & IgG1 & PE & DAKO & 99.2 \\
\hline Negative control & IgG1 & FITC/PE & DAKO & 0 \\
\hline Negative control & $\operatorname{IgG} 2 \mathrm{a}$ & FITC & DAKO & 0 \\
\hline Negative control & $\operatorname{IgG} 2 b$ & $\mathrm{PE}$ & Miltenyi & 0 \\
\hline
\end{tabular}

chamber (Beckman Coulter GmbH, Krefeld, Germany). Approximately $2 \times 10^{8}$ SCCOHT-derived cells in an exponential growth phase were harvested, resuspended in PBS and applied to the standard chamber $\left(1,600 \mathrm{rpm}\right.$ at $\left.24^{\circ} \mathrm{C}\right)$ using a digital flow controller (Cole-Palmer Instruments Inc., Chicago, IL, USA). Subsequent fractions of $100 \mathrm{ml}$ aliquots of the elutriated samples were collected upon progressive increase of the pump speed. Elutriated cell fractions were examined for viability, cell number and cell size distribution in a Vi-CELL Series Cell Viability Analyzer (Beckman Coulter $\mathrm{GmbH}$ ).

Cell cycle analysis. The cell cycle analysis was performed as described previously (24). Briefly, $5 \times 10^{5}$ SCCOHT-derived cells were fixed in $70 \%(\mathrm{v} / \mathrm{v})$ ice-cold ethanol at $4^{\circ} \mathrm{C}$ for $24 \mathrm{~h}$. Thereafter, the fixed cells were stained with CyStain DNA 2 step kit (Partec $\mathrm{GmbH})$ and filtered through a $50 \mu \mathrm{m}$ filter. The samples were then analyzed in a Galaxy flow cytometer (Partec $\mathrm{GmbH}$ ) using the MultiCycle cell cycle software (Phoenix Flow Systems Inc., San Diego, CA, USA).
Cytogenetic investigations. Chromosome preparation and fluorescence-R banding were performed as previously described (25). Twenty-five metaphases were analysed in the SCCOHT-derived cells. Karyotypes were described according to the International System for Human Cytogenetic Nomenclature (26).

Fluorescence in situ hybridization (FISH). FISH was performed according to standard procedures (probes supplied by Abbott, Wiesbaden, Germany) (27). For each FISH analysis, at least 200 interphase nuclei were analyzed.

Multicolor fluorescence in-situ hybridization (mFISH). mFISH analysis was carried out using an mFISH kit (MetaSystems, Altlussheim, Germany). The mFISH procedure was performed according to the manufacturer's instructions. Metaphase spreads that had been used for karyotyping were destained in a decreasing ethanol series $(99 \%, 95 \%, 70 \%$, $50 \%$ ) and hybridized with the SpectraVysion ${ }^{\mathrm{TM}} 24$ chromosome painting kit (Abbott). The mFISH procedure was 
performed according to the manufacturer's instructions. Fluorochromes were sequentially captured using specific single-band pass filters in a Zeiss Axioplan 2 microscope (Zeiss, Jena, Germany). mFISH ISIS software (MetaSystems, Altlussheim, Germany) was used for image analysis.

DNA extraction. Cell pellet obtained by centrifugation $(800 \mathrm{~g}$, $5 \mathrm{~min})$ was resuspended in $400 \mu \mathrm{l}$ of STE buffer $(50 \mathrm{mM}$ Tris-HCl, $1 \mathrm{mM}$ EDTA, $100 \mathrm{mM} \mathrm{NaCl}, \mathrm{pH}$ 7.5) containing Proteinase K (final concentration $3.75 \mathrm{mg} \mathrm{ml}^{-1}$ ) and $0.5 \%(\mathrm{v} / \mathrm{w})$ SDS (sodium dodecyl sulphate). The samples were incubated at $56^{\circ} \mathrm{C}$ over night. Then $400 \mu 1$ of phenol-chloroform-isoamylalcahol (25:24:1) (saturated with $10 \mathrm{mM}$ Tris- $\mathrm{HCl}, \mathrm{pH}$ 8.0) were added to each mixture. Samples were incubated $10 \mathrm{~min}$ on ice and centrifuged $\left(13,200 \mathrm{rpm}, 10 \mathrm{~min}, 4^{\circ} \mathrm{C}\right)$. The aqueous phase was recovered and a second time mixed with $400 \mu \mathrm{l}$ of phenol-chloroform-isoamylalcohol, incubated for $10 \mathrm{~min}$ on ice and centrifugated $\left(13,200 \mathrm{rpm}, 10 \mathrm{~min}, 4^{\circ} \mathrm{C}\right)$. Then the aqueous phase was recovered with $400 \mu$ l chloroform, resolved carefully, incubated $10 \mathrm{~min}$ on ice and centrifuged (13,200 rpm, $10 \mathrm{~min}$, $\left.4^{\circ} \mathrm{C}\right)$. Nucleic acids were precipitated with 0.1 volume NaAcetate (3 M) and 2.5 volume ethanol (100\%) and incubated for $30 \mathrm{~min}$ on ice. The precipitate was then washed with $70 \%$ ethanol and resuspended in $50 \mu \mathrm{l}$ of deionized water.

Array-CGH. Array-CGH was performed using the Agilent Human Genome Microarray Kit 400A (Agilent Technologies, Santa Clara, CA, USA), a high resolution 60-mer oligonucleotide based microarray with median overall probe spacing of about $5 \mathrm{~kb}$. Labeling and hybridization of genomic DNA was performed according to the protocol provided by Agilent. Briefly, $1 \mu \mathrm{g}$ of test DNA and reference DNA each were labeled by random priming using the Agilent Genomic DNA Labeling Kit Plus, test DNA with Cy3-dUTP and reference DNA with Cy5-dUTP. Labeled products were purified by amicon ultra $0.5 \mathrm{ml} 30 \mathrm{~K}$ centrifugal filters (Millipore, Billerica, MA, USA), combined and then mixed with human Cot-1 DNA (50 $\mu \mathrm{g})$, Agilent 10X blocking Agent, and Agilent 2X Hybridization Buffer. This solution was hybridized to Agilent's 400K Human Genome CGH microarray at $65^{\circ} \mathrm{C}$ with $20 \mathrm{rpm}$ rotation for $40 \mathrm{~h}$. Washing steps were performed according to the Agilent protocol. Microarray slides were scanned immediately using an Agilent microarray scanner. For image analysis, default CGH settings of Feature Extraction Software (Agilent Technologies, Waldbronn, Germany) were applied. Output files from Feature Extraction were subsequently imported into Agilent's CGH data analysis software, DNA-Workbench. The Aberration Algorithm ADM2 was applied and Aberration Filters were set to: at least 50 probes with mean $\log 2$ Ratio $=0.3$.

Lentiviral transduction of SCCOHT-1 with the GFP gene. The construction, testing and production of lentiviral vectors for gene transfer have been described previously (28). In brief, a 3rd generation lentiviral vector encoding the green fluorescent protein (GFP) driven by an internal spleen-focus forming SFFV U3 promoter (pRRL.PPT.SF.GFPpre) was co-transfected together with HIV-1 gag/pol, RSV-Rev and VSV glycoprotein expression plasmids. The infectious lentiviral vector particles were harvested 48 to $72 \mathrm{~h}$ post transfection and subsequently stored at $-80^{\circ} \mathrm{C}$ until usage. Next, $1 \times 10^{5} \mathrm{SCCOHT}$-derived cells/ well were incubated in culture medium in a 6-well plate and lentiviral transduction was performed. Following addition of the virus at an MOI5 in the presence of protamine sulphate, the plates were immediately centrifuged $\left(2,000 \mathrm{rpm} / 30 \mathrm{~min} / 4^{\circ} \mathrm{C}\right)$ followed by an incubation at $37^{\circ} \mathrm{C} / 5 \% \mathrm{CO}_{2}$ in a humidified atmosphere for $24 \mathrm{~h}$. Thereafter, the medium containing the virus particles was removed and the tranduced cells were cultured further on with new medium. The successful transduction of the GFP gene was examined under a fluorescence microscope.

In vivo experiments. Animal research using NOD/scid mice was carried out by following internationally recognized guidelines on animal welfare and has been approved by the institutional licensing committee ref. no. 33.9-4250204-06/1178 on Sept. 22th, 2010. About $1 \times 10^{6}$ GFP-labeled SCCOHT-derived cells of the elutriation fractions were injected subcutaneously into 5 to 6 weeks-old female NOD/ scid mice. After 4 to 8 weeks of SCCOHT-1 injection, the mice had developed large subcutaneous tumors and were sacrificed by $\mathrm{CO}_{2}$ anesthesia and cervical dislocation. Following UV light examination for the detection of GFP positive tissue, the tumors were dissected, weighed and washed in PBS supplemented with $100 \mathrm{U} / \mathrm{ml}$ penicillin and $100 \mu \mathrm{g} / \mathrm{ml}$ streptomycin. Thereafter, the tumor tissue was minced with a scalpel into approximately $2 \mathrm{~mm}^{3}$ large tissue pieces, washed again and incubated in growth culture medium to obtain primary cultures of the NOD/scid mouse tumors. In parallel, parts of the mouse tumor tissue were fixed in $4 \%$ glutardialdehyde solution for histopathological evaluations.

For calcium measurements retroorbital blood was taken from NOD/scid mice which had developed an SCCOHT-1 cell-derived subcutaneous tumor and serum was prepared and analyzed for $\left(\mathrm{Ca}^{2+}\right)$ concentration using the Arsenazo Reagent (Beckman Coulter $\mathrm{GmbH}$ ) in an AU400 Chemistry System (Beckman Coulter $\mathrm{GmbH}$ ). According to the manufacturer's manual, the procedure is based on $\left(\mathrm{Ca}^{2+}\right)$ reacting with Arsenazo III [2,2'-(1,8-Dihydroxy-3,6-disulphonaphthylene-2,7-bisazo)bisbenzenear-sonic acid] to form an intense purple-colored complex. Magnesium does not significantly interfere in calcium determination using Arsenazo III. In this method the absorbance of the $\left(\mathrm{Ca}^{2+}\right)$-Arsenazo III complex is measured bichromatically at $660 / 700 \mathrm{~nm}$. The resulting increase in absorbance of the reaction mixture is directly proportional to the calcium concentration in the sample.

Telomerase assay. The activity of this nuclear enzyme in SCCOHT-1 cells was detected by TRAPeze telomerase detection kit (Millipore, Beverly, MA, USA) in a radioactive assay. Briefly, homogenates of SCCOHT-1 cells and tumor tissue from NOD/scid mice was resuspended in CHAPS lysis buffer and combined with the reaction mixture including a $\left[\gamma_{-}{ }^{32} \mathrm{P}\right]$ ATP radiolabeled TS primer which has been previously labelled with T4-polynucleotide kinase (New England BioLabs, Beverly, MA, USA). Evaluation and adjustment of equal protein was performed using the Bradford method (Bio-Rad Inc., Richmond, CA, USA). The different SCCOHT samples were subjected to PCR amplification according to the manufacturer's instructions using Taq DNA polymerase (New England BioLabs). Thereafter, loading dye was added to the amplified DNA and the samples were loaded onto a $10 \%$ non-denaturing polyacryl- 

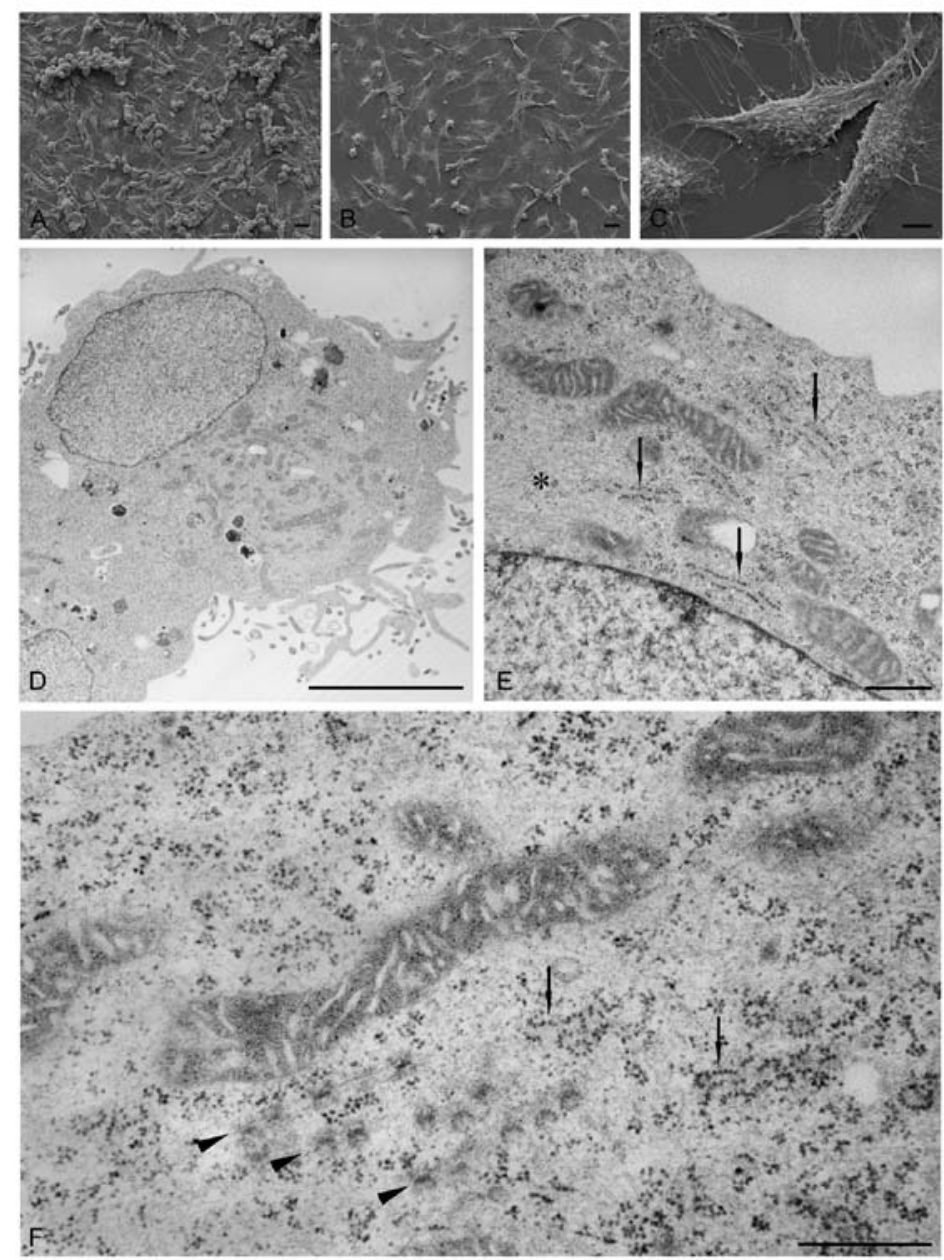

Figure 1. Morphology of SCCOHT-1 cells. Scanning (A-C) and transmission (D-F) electron microscopy of cultivated SCCOHT-1 cells. (A) Low power SEM micropgraph of cells grown to confluence. Most of the cells show a spindle-shaped outline. Some rounded cells have clustered to form wall-like three-dimensional structures. (B) Low power SEM showing subconfluently grown cells. Most cells spread on the cover slip are spindle-shaped, some are spherical. (C) SEM at higher magnification. The apical surface of the cells is marked by membranous protrusions. Numerous filopodia extending from the cells and attached to the supporting cover slip are visible. (D) Transmission electron micrograph of cultured cells. The nucleus is rich in euchromatin. Mitochondria are abundant and of different sizes. The plasma membrane shows numerous extensions of variable length and diameter corresponding to the filopodia and surface protrusions seen by SEM and sectioned in different planes. (E) TEM. Higher magnification showing mitochondria with distinct cristae. Some cisternae of the rough endoplasmic reticulum are visible (arrows) but a large number of ribosomes appears to be free in the cytoplasm. The asterisk marks an area with abundant cytoskeletal filaments. Note the nucleus at the lower edge of the image showing predominantly euchromatin. (F) TEM. Well developed mitochondria surrounded by ribosomes, small tubules of the rough endoplasmic reticulum and some annulate lamellae (arrowheads). Bars ${ }^{\mathrm{a}, \mathrm{b}}, 20 \mu \mathrm{m}$; ${ }^{\mathrm{c}, \mathrm{d}}, 5 \mu \mathrm{m}$; ${ }^{\mathrm{e}, \mathrm{f}}, 0.5 \mu \mathrm{m}$.

amide gel. Following electrophoresis, the gel was dried and the radioactive bands were visualized in a PhosphorImager (Storm 820, Amersham Biosciences, Piscataway, NJ, USA).

\section{Results}

Morphological evaluation of SCCOHT-1. SEM (Fig. 1A-C) revealed predominantly spindle-shaped adherent cells and some spherical cells. When grown to high confluency the more spherical cells occasionally formed wall-like three-dimensional clusters (Fig. 1A). Although spherical cells were present at subconfluent densities as well no formation of three-dimensional clusters could be observed (Fig. 1B). Especially the abundant spindle-shaped cells showed numerous filopodial extensions spread on the support. In addition the cells were rich in membranous protrusions at their apical surface (Fig. 1C).

Thin section electron microscopy showed flat cells attached to the bottom of the Petri dish and cells with a more round profile. In sections cut perpendicular to the dish surface, the latter cells were often located in a higher position compared to the flat cells. All cells showed numerous filopodia extending from their circumference (Fig. 1D). The sectioned nuclei frequently contained nucleoli and the chromatin was mostly in an extended (euchromatic) state (Fig. 1D and E). Within the cells abundant and often elongated mitochondria were conspicuous (Fig. 1D-F). A large number of ribosomes occurred free within the cytoplasm. However, some were associated to short cisternae or tubules of the endoplasmic reticulum (Fig. 1E and F). Occasionally, annulate lamellae could be detected (Fig. 1F). Both, filamentous and tubular components of the cytoskeleton were regularly observed.

Cell surface marker analysis and intermediate filaments. Flow cytometric analysis of 22 different cell surface proteins and 2 types of intermediate filaments was performed according to the antibody specificities indicated in Table I and revealed only 6 


\section{SCCOHT-1 surface marker and intermediate filaments}
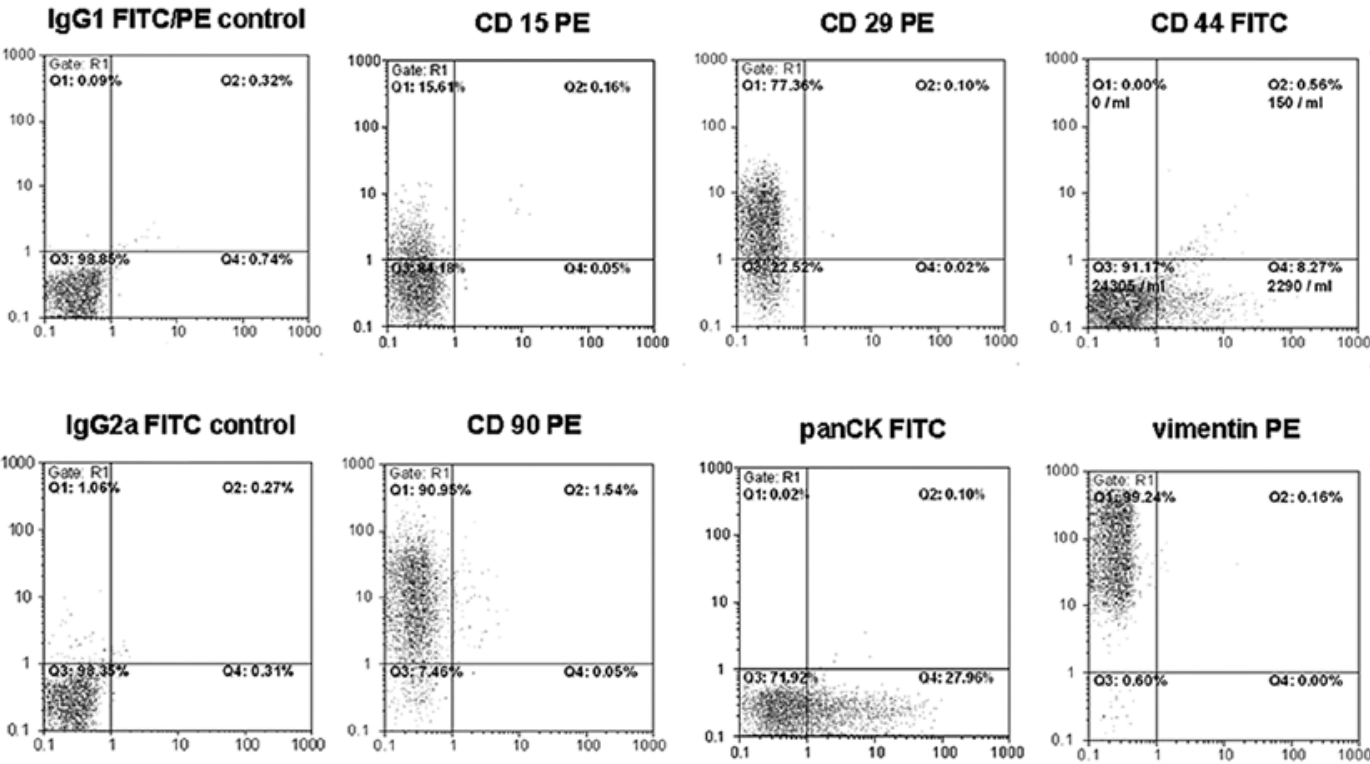

Figure 2. Cell surface markers and filament expression. Flow cytometric analysis of the expression levels of the cell surface markers CD15, CD29, CD44 and CD90 in SCCOHT-1 cells. Likewise, the detection of the intermediate filaments cytokeratin (panCK) and vimentin was performed. Control fluorescence was presented by the appropriately labelled IgG subclass antibodies (IgG1 FITC/PE and IgG2a FITC).

partially positive reactions. Thus, about $15.6 \%$ of the SCCOHT-1 cells expressed the epitope of CD15 representing a carbohydrate adhesion molecule (3-fucosyl-N-acetyl-lactosamine) which can be associated with surface glycoproteins and/or glycolipids (Fig. 2). Moreover, 77.4\% of SCCOHT-1 cells expressed CD29. Expression of the CD44 antigen was detectable on $8.3 \%$ of the population and the CD90 marker was represented by $91 \%$ of the SCCOHT-1 cells (Fig. 2). With respect to intermediate filaments, the pan-cytokeratin antibody tested positive in $28.2 \%$ of the cells and vimentin was present in all SCCOHT-1 cells (99.2\%) (Fig. 2). These expression levels on SCCOHT-1 cells did not alter during long-term culture and revealed similar results in populations cultured for 136, 230 and 382 days, respectively. Likewise, culture of SCCOHT-1 cells under hypoxic $\left(5 \% \mathrm{O}_{2}\right)$ conditions had little if any effect on the expression patterns as compared to the normoxic $\left(21 \% \mathrm{O}_{2}\right)$ environment (data not shown).

Proliferation. The proliferative capacity of SCCOHT-1 was initially tested under different conditions. A comparison of culture medium supplemented with either human $A B$ serum or fetal calf serum demonstrated the requirement of serum addition for optimal growth conditions, however, no significant difference was detectable in the use of the xeno-free (Fig. 3A). Therefore, $10 \%$ FCS was used as standard culture condition for SCCOHT-1 cells and revealed an average population doubling of $38.1 \mathrm{~h}(\mathrm{n}=4)$. An optimization of the cell density revealed a cell concentration of about $1 \times 10^{5}$ cells $/ \mathrm{ml}$. The culture of SCCOHT-1 cells in a hypoxic microenvironment $\left(5 \% \mathrm{O}_{2}\right)$ as compared to the normoxic culture conditions $\left(21 \% \mathrm{O}_{2}\right)$ for more than 7 days demonstrated little if any differences in the proliferative capacity (data not shown).

Flow cytometric cell cycle analysis of logarithmicallygrowing SCCOHT-1 cells revealed a distribution of continuously proliferating cells with about $67 \%$ in $\mathrm{G}_{0} / \mathrm{G}_{1}$ phase, $13 \%$ in S phase and $20 \%$ in the mitotic $\mathrm{G}_{2} / \mathrm{M}$ phase as evaluated by the MultiCycle cell cycle software (Fig. 3B). Following separation and cell size enrichment of SCCOHT-1 by centrifugal counterflow elutriation (CCE), however, subsequent analysis of the cell cycle phases could distinguish two separate peaks in both, the $\mathrm{G}_{0} / \mathrm{G}_{1}$ and $\mathrm{G}_{2} / \mathrm{M}$ phase, respectively, suggesting that SCCOHT-1 cells represent a mixture of at least two subpopulations (Fig. 3B).

Classical cytogenetic analysis, $m F I S H$ and array-CGH analysis. According to the distinguishable subpopulations in the cell cycle analysis, the question was addressed as to whether potential chromosomal aberrations may be associated with the SCCOHT-1 cells. Thus, classical cytogenetic analysis and mFISH of the SCCOHT-1 metaphase chromosomes was performed and revealed an unbalanced translocation between chromosome 6 and chromosomes $17 \operatorname{der}(6) t(6 ; 17)(q 26 ; q 22)$ in 3 out of 21 metaphases (Fig. 4A). Eighteen metaphases showed a normal karyotype.

The genetic stability was further investigated in a more detailed analysis between 139 and 321 days-old SCCOHT-1 populations using a DNA array CGH analysis (Fig. 4B). Under the given filter criteria 8 focal genomic alterations were detected in the 139-day-old and 21 alterations in the 321-dayold culture population. Among them were a deletion in $6 \mathrm{q} 26$ (162.528 Mb-162.902 Mb) including the PARK2 gene, a deletion in 8p23.2 (3.502 Mb-3.678 Mb) including the CSMD1 gene and a deletion of 12p13.1 (14.016 Mb-14.546 Mb) including the genes GRIN2B and ATF7IP. These alterations were observed in the 321-day-old, but not in the early SCCOHT-1 population.

Additional alterations were observed during culture, among them a duplication $19 \mathrm{p} 13.3(0.280 \mathrm{Mb}-2.445 \mathrm{Mb})$ adjacent to 
A

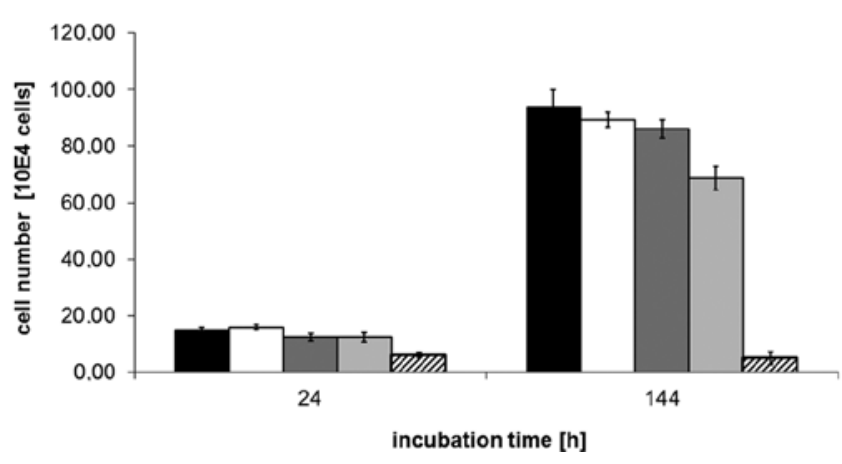

B

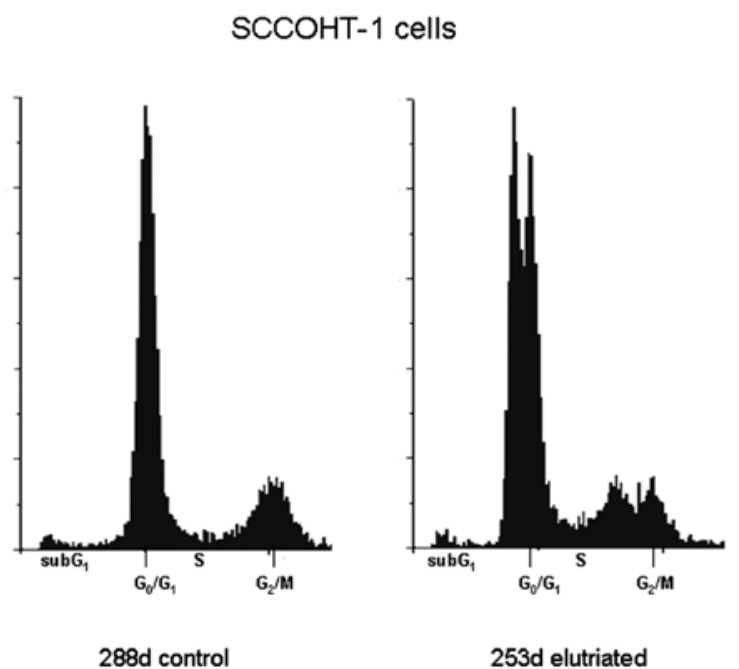

Figure 3. Proliferation of SCCOHT-1. (A) The SCCOHT-1 cells were incubated in culture medium in the presence of $10 \%$ human $\mathrm{AB}$ serum (black bars), $10 \%$ fetal calf serum (white bars), $5 \%$ human $\mathrm{AB}$ serum (dark grey bars), $5 \%$ fetal calf serum (light grey bars), and without addition of any serum (striped bars) for 24 and $144 \mathrm{~h}$, respectively, and the number of viable cells was evaluated by trypan blue exclusion in a hemocytometer. Data represent the mean \pm SD of 3 independent experiments. (B) Cells in logarithmic growth phase were analysed for the different cell cycle phases in a 288-day-old SCCOHT-1 original population (control) and in a 253-day-old SCCOHT-1 culture after CCE (elutriated). The cell cycle histograms were analyzed using the MultiCycle cell cycle software.

a deletion in 19p13.3 (2.461 Mb-4.546 Mb) (Fig. 4B). A $3 \mathrm{Mb}$ duplication of the region 11p15.5-15.4 was present in both populations. To validate the results of the aCGH an additional FISH on interphases was perfomed. A submicroscopic deletion of the subtelomeric region 19p could be detected in $14 \%$ and a submicroscopic trisomy and tetrasomy of the subtelomeric region of $11 \mathrm{p}$ could be detected in $10 \%$ and $88 \%$ of the interphase nuclei, respectively.

SCCOHT-1-induced NOD/scid mouse tumors. In order to investigate the tumorigenic potential of SCCOHT-1, $1 \times 10^{6}$ cells of a GFP-labeled population after lentiviral transduction was injected subcutaneously into NOD/scid mice. Following injection of 7 mice with the SCCOHT- 1 cells and 6 elutriated fractions, all 7 mice developed a significant subcutaneous tumor within 4 to 8 weeks (Fig. 5). The tumor weight in relation to the mouse weight varied between $0.43 \%$ and $8.92 \%$ in
Table II. Tumor weight in NOD/scid mice.

\begin{tabular}{lccc}
\hline $\begin{array}{l}\text { Injected } \\
\text { population }\end{array}$ & $\begin{array}{c}\text { Mouse } \\
\text { weight } \\
(\mathrm{g})\end{array}$ & $\begin{array}{c}\text { Tumor } \\
\text { weight } \\
(\mathrm{g})\end{array}$ & $\begin{array}{c}\text { Relation tumor } \\
\text { weight/mouse } \\
\text { weight }(\%)\end{array}$ \\
\hline $\begin{array}{l}\text { SCCOHT-1 } \\
\text { control }\end{array}$ & 18.92 & 0.374 & 1.98 \\
$\begin{array}{l}\text { SCCOHT-1 } \\
\text { elutriated-1 }\end{array}$ & 23.37 & 0.1 & 0.43 \\
$\begin{array}{l}\text { SCCOHT-1 } \\
\text { elutriated-3 }\end{array}$ & 22.68 & 0.136 & 0.6 \\
$\begin{array}{l}\text { SCCOHT-1 } \\
\text { elutriated-4 }\end{array}$ & 17.82 & 1.59 & 8.92 \\
$\begin{array}{l}\text { SCCOHT-1 } \\
\text { elutriated-5 }\end{array}$ & 11.06 & 0.601 & 5.43 \\
$\begin{array}{l}\text { SCCOHT-1 } \\
\text { elutriated-6 }\end{array}$ & 23.4 & 0.095 & 0.41 \\
$\begin{array}{l}\text { SCCOHT-1 } \\
\text { elutriated-7 }\end{array}$ & 17.82 & 0.24 & 1.35 \\
\hline
\end{tabular}

the different elutriated cell fractions as compared to $1.98 \%$ in the original SCCOHT-1 control cells (Table II). Fluorescence scanning of the organs revealed at least one mouse (elutriated-4) carrying liver metastasis. Blood serum analysis for calcium concentrations revealed $3.36 \mathrm{mmol} / 1\left(\mathrm{Ca}^{2+}\right)$ in a SCCOHT-1 tumor carrying mouse whereby normal control NOD/scid mice exhibit levels of $2.75 \pm 0.15 \mathrm{mmol} / 1\left(\mathrm{Ca}^{2+}\right)$. The mice were sacrificed and the mouse tumors were dissected for both, immunohistochemical analysis and tissue culture, respectively. After re-cultivation of the minced NOD/scid mice-derived tumors using SCCOHT-1 culture medium in an explant culture, continuously proliferating primary cultures from all tumors were obtained, termed SCCOHT-1-GFP ${ }^{\mathrm{NOD} /}$ scid. These cells from re-cultivated NOD/scid mice-derived tumors were cultured so far for at least 213 days and demonstrated no significant differences as compared to the original SCCOHT-1 cells and one representative population was subjected in a telomerase assay to test the continuous growth activities in the cells.

Telomerase assay. SCCOHT-1 cells cultured for 151 and 396 days demonstrated a strong telomerase activity which sustained in 514 days-old SCCOHT-1 cells carrying the GFP gene after lentiviral transduction (Fig. 6). This SCCOHT-1 telomerase measurement revealed similar activity levels according to the positive HeLa assay control and each sample included an appropriate heat-sensitive control $(\Delta \mathrm{T})$ (Fig. 6). Moreover, lysates from NOD/scid mouse-dissected SCCOHT1-derived tumor tissue also represented telomerase activity although at markedly reduced levels. In addition, re-cultured cells from explant cultures of NOD/scid mouse-derived SCCOHT-1 tumors (SCCOHT-1-GFP ${ }^{\text {NOD/scid }}$ ) revealed a similarly high telomerase activity as compared to the original SCCOHT-1 cells suggesting a constantly remaining and stable proliferative capacity also after xenograft (Fig. 6). 

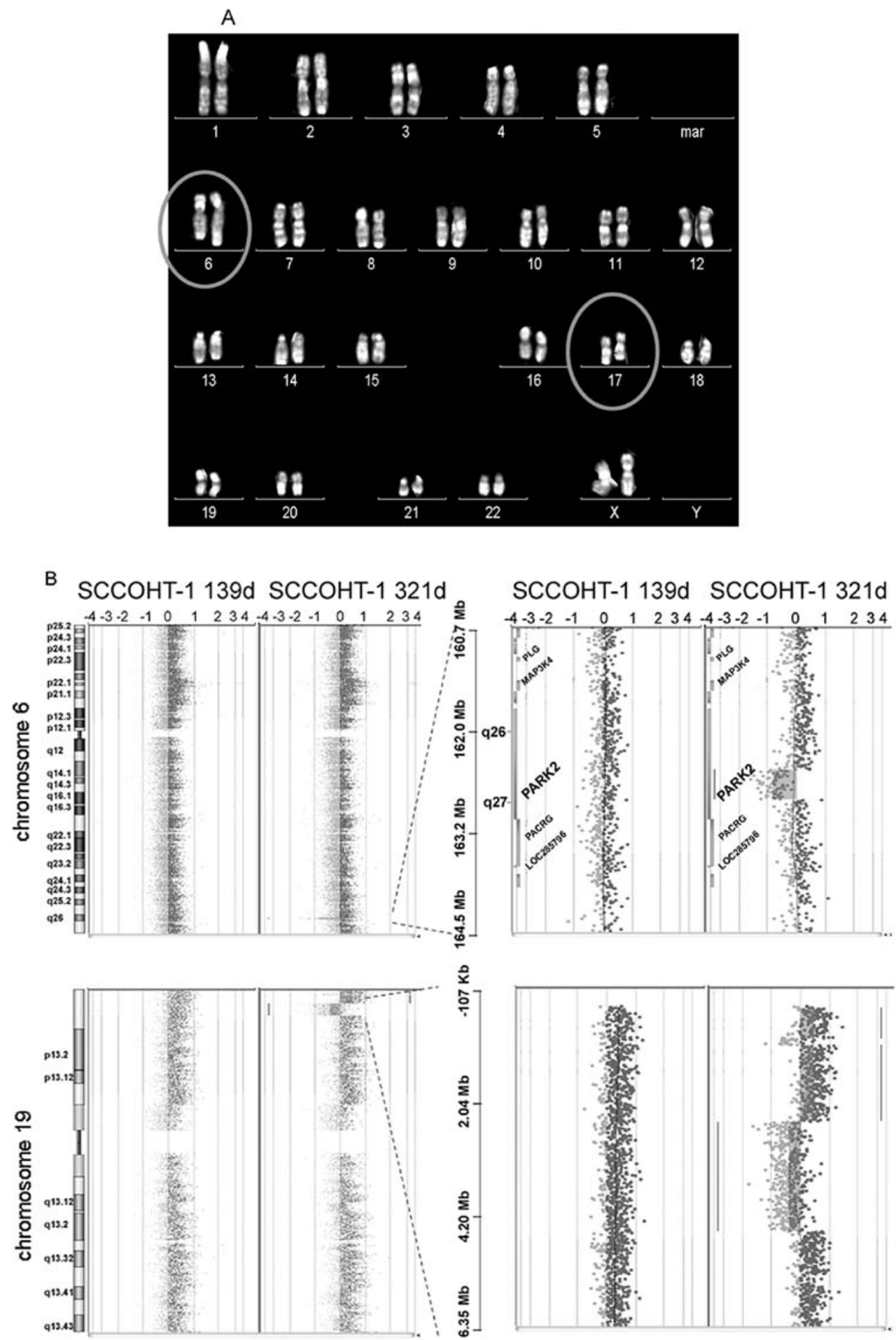

Figure 4. Karyotype analysis. (A) Classical banding analysis and mFISH. Metaphase after fluorescence-R-banding is demonstrated. In 3 out of 21 metaphases an unbalanced translocation der(6)t(6:17) could be detected (circles) by multicolor fluorescence in situ hybridization (m-FISH) resulting in a partial deletion of 6 and partial trisomy of 17. ISCN-Karyotype: 46,XX,der(6)t(6;17)(q26;q22)[3]/46,XX[18]. (B) Array CGH. DNA samples of 139 and 321-day-old SCCOHT-1 populations were hybridized to a 400K Human Genome CGH microarray. For breakpoint calling aberration filters within DNA analytics were set to: algorithm ADM-2 threshold 6.0, aberration filter 50_log0.3_hg19; upper part: microdeletion in 6q26: next to the ideogram of chromosome 6, the genomic profile for the whole chromosome 6 is shown, the region of deletion is zoomed in from $160.7 \mathrm{Mb}$ to $164.5 \mathrm{Mb}$ including the PARK2 gene (right part); lower part: the genomic profile of chromosome 19 next to the ideogram with a terminal deletion/gain in the p-arm, altered region zoomed in from 1.07 Mb to $6.35 \mathrm{Mb}$. Due to the large number of genes in this region, names of gene are not shown.

Immunohistochemical analysis. Tumor sections of the NOD/ scid mouse-derived SCCOHT-1-GFP-induced tumors were compared to appropriate sections of the original SCCOHT patient tumor by immunohistopathological evaluation (Fig. 7). The tumor sections of both sources were stained with a neuroendocrine marker (NCAM/CD56) and with an 


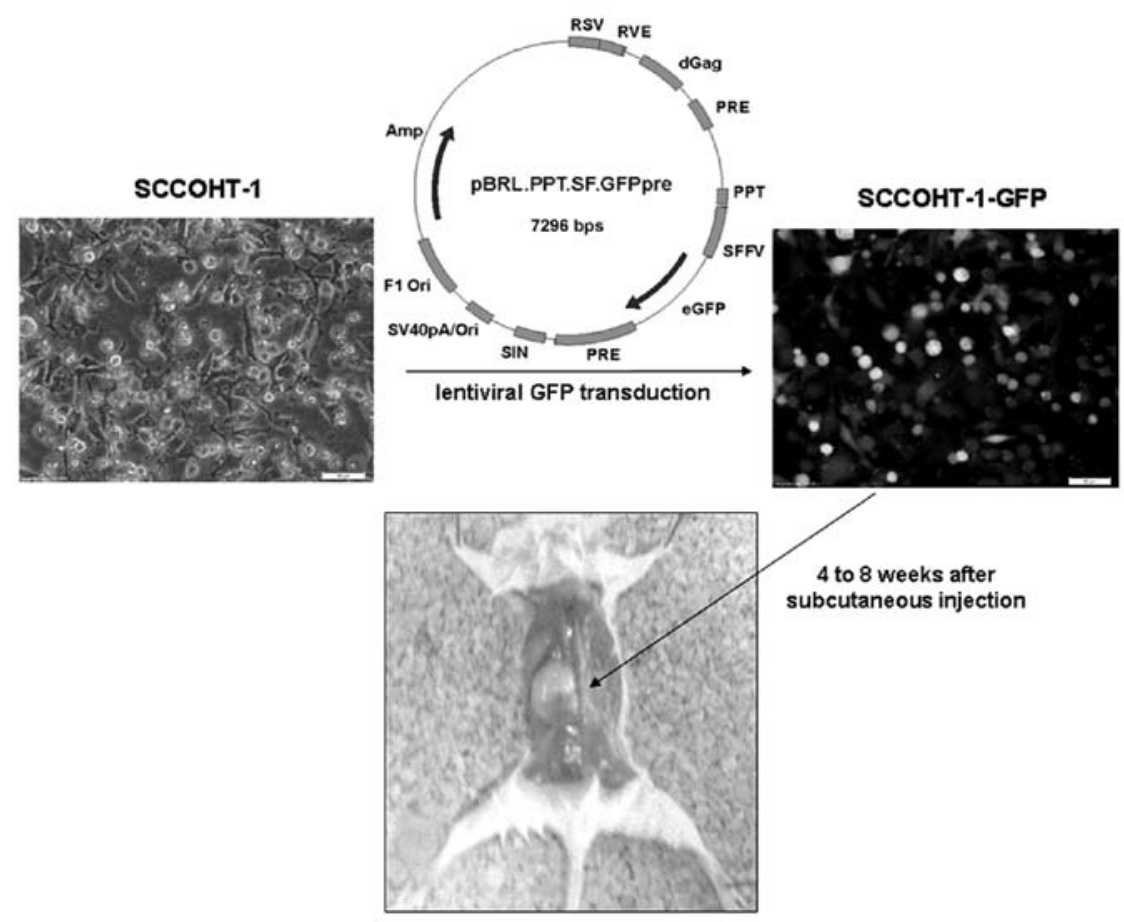

Figure 5. GFP vector transduction and in vivo analysis. Following lentiviral transduction of SCCOHT-1 cells with a GFP gene-carrying vector and subsequent elutriation, $1 \times 10^{6}$ cells of the GFP-labeled control population and the 6 elutriated populations were injected subcutaneously into NOD/scid mice, respectively. Within 4 to 6 weeks after SCCOHT-1-GFP injection, all of the mice developed a significant subcutaneous tumor and one representative animal out of seven is documented.

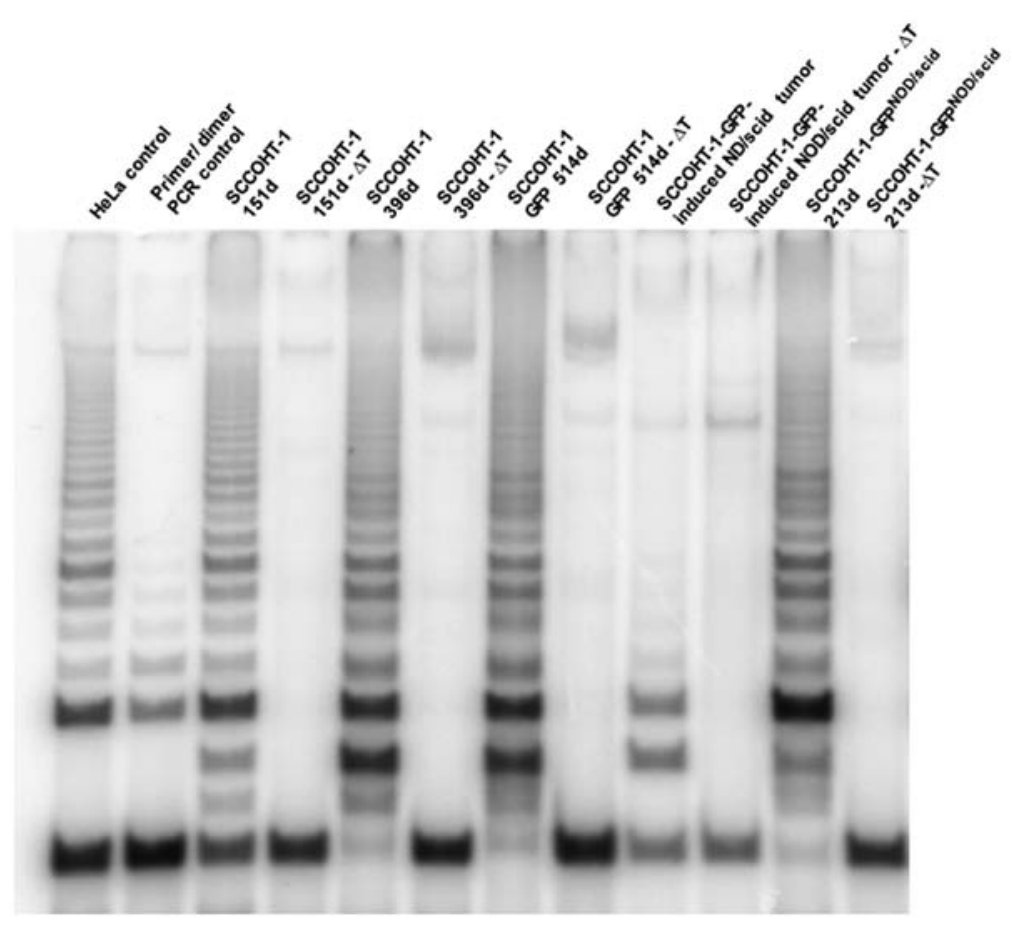

Figure 6. Telomerase activity. SCCOHT-derived cells and tumor tissue were subjected to the TRAPeze telomerase assay. Thus, SCCOHT-1 after 151 and 396 days of culture were compared to lentiviral GFP-transfectants SCCOHT-1-GFP after 514 days. Moreover, tumor tissue dissected from NOD/scid mice after injection of SCCOHT-1-GFP was tested and SCCOHT-1-GFP NOD/scid cells after 213 days which represents the cell culture obtained after re-culturing of the NOD/scid mouse tumors. Appropriate positive and corresponding heat-inactivated negative controls $(\Delta \mathrm{T})$ were applied to the assay. d, days.

anti-cytokeratin antibody (pan-CK) and revealed similar expression patterns. Moreover, the cells within the tumor tissue were stained with hematoxylin and eosin (H\&E) and revealed a comparable morphology and distribution in the mouse-derived tumors as compared to the original tumor tissue of the patient (Fig. 7). 


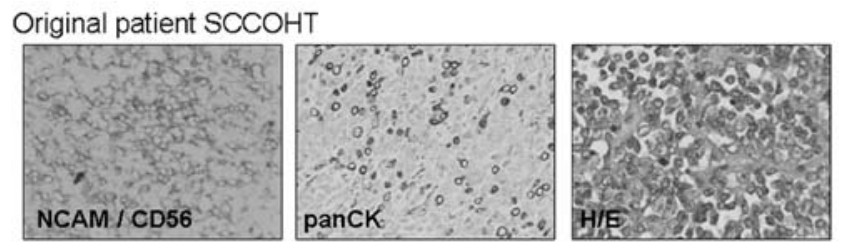

Mouse-derived tumor from SCCOHT-1

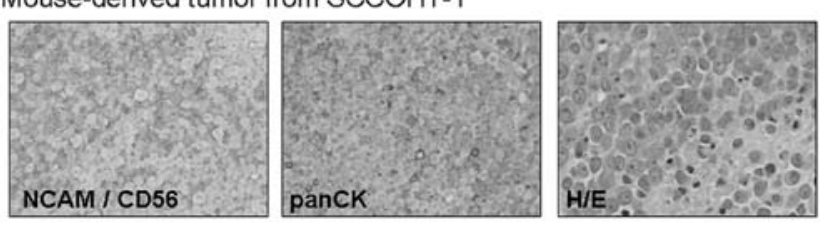

Figure 7. Immunohistochemistry. The mouse-derived tumors after SCCOHT-1 injection were compared to the original SCCOHT patient tumor by immunohistochemical analysis. The neuroendocrine marker NCAM/CD56 and the expression of cytokeratins (pan-CK) were compared.

\section{Discussion}

SCCOHT represents an aggressive female tumor with poor prognosis, and the present study introduces and characterises the first cellular model for this devastating disease. With respect to morphology the large number of rounded cells shown by both SEM and TEM is concomitant with rapidly and frequently dividing cells, a well-known feature of malignant tumor cells. This is further supported by the observation of annulate lamellae which tend to occur in rapidly dividing cells and at early stages of differentiation. The predominantly euchromatic state of the chromatin in conjunction with the large amount of ribosomes indicate high activity in protein synthesis. However, the prevalence of free ribosomes suggests synthesis of structural proteins needed for cell growth rather than proteins destined for secretion. Together, the ultrastructural features displayed by the cells are concomitant with rapid division, early stages of differentiation and active synthesis of structural proteins. These morphological findings are also supported by the functional data demonstrating a continuous proliferative capacity by permanent cell cycle traverse and a persisting telomerase activity whereby the SCCOHT-1 cells displayed a stable karyotype.

Moreover, the morphological characterization also correlates with the expression of surface markers of a more undifferentiated phenotype. Indeed, SCCOHT-1 cells demonstrated a scarce expression pattern of the cell surface markers and filaments tested in this study. Thus, only a minor population expressed cytokeratins, the adhesion molecule CD15 and the cellular communication hyaluronic acid receptor CD44. The majority of SCCOHT- 1 cells exhibited the $\beta-1$ integrin subunit CD29 which also functions in cell-cell communication, i.e. as the $\alpha 3 \beta 1$ integrin, and may play a role during metastatic diffusion of certain tumor cells. The appearance of the neuroendocrine marker CD56 in the SCCOHT specimen has also been discussed as one of the markers in other types of ovarian cancers including ovarian granulose cell tumors and ovarian sex cord-stromal tumors $(29,30)$.

Nearly all SCCOHT-1 cells expressed the intermediate filament vimentin and the CD90 antigen which represents a glycophosphatidylinositol-anchored membrane protein in the outer leaflet of lipid rafts, suggesting intense cell-cell and cell-matrix interactions. A variety of immune competent cells express CD90 such as precursor T cells (thymocytes), $\mathrm{T}$ cells and some NK cell populations. Moreover, CD90 can be expressed by hematopoietic stem cells and it is predominantly present on mesenchymal stem cells in a normoxic and hypoxic microenvironment $(31,32)$. Using a tumor model during induced epithelial to mesenchymal transition of non-small cell lung cancer cells, a reduction in cytokeratins and E-cadherin has been detected concomitant with a progressively increased expression of CD90 and vimentin (33) indicating that the SCCOHT-1 cells may represent an intermediate state between the epithelial and mesenchymal phenotype. However, no genetic origin of SCCOHT has been identified to date and accordingly, little is known about potential mutations in SCCOHT and the corresponding patients.

Certain genetic alterations including BRCA gene mutations which play a major role in hereditary breast cancer development are also discussed for some ovarian cancers. Some cases were reported about familial SCCOHT, however, no simultaneous BRCA mutations were detectable (34) suggesting significant differences between ovarian cancer-types and SCCOHT. Moreover, the absence of $12 p$ aberrations would rule out a germ cell tumor-derived neoplasm since $12 p$ gain represents a pathognomonic marker of malignant germ cell tumors. The chromosomal imbalances observed particularly in long-term cultured SCCOHT-1 cells in the present study, included deletions of the CSMD1, GRIN2b, ATF7IP and the PARK2 gene, respectively. The PARK2 gene product represents the E3 ubiquitin protein ligase (parkin) involved in the regulation of proteasomal protein turnover. In SCCOHT-1 cells, the breakpoint $6 \mathrm{q} 26$ including parkin is associated with the translocation $\mathrm{t}(6 ; 17)$ (q26:q22) as determined by metaphase cytogenetics. Previous work suggested that $P A R K 2$ which is located within a fragile area of chromosome 6, may exhibit certain tumor suppressor function as it is also deleted in a large amount of ovarian and lung cancer patients (35). Likewise, the CSMDI gene product has been attributed with tumor-suppressive properties since deletion of this gene in invasive ductal breast cancer patients has been reported with high malignancy and poor survival (36). GRIN2b among other genes (i.e. HOXA1, MTIG and SFRP4) represents a methylation marker during progression of breast cancer (37). The ATF7IP gene encodes for ATFa-associated modulator (AM) and activating transcription factor 7-interacting protein, a regulator of telomerase reverse transcriptase expression and previous work has demonstrated that variants near ATF7IP are accompanied with testicular germ cell cancer (38).

Besides these characterized chromosomal imbalances SCCOHT-1 cells exhibit a stable phenotype which is also determined by metaphase cytogenetics. The stability of these progressively proliferating tumor cells is further verified by the in vivo experiments demonstrating high tumorigenicity in all NOD/scid mice and a histopathology of the mouse tumors which corresponded to the original patient tumor biopsy. Moreover, induction of SCCOHT-1-induced tumors in NOD/scid mice was associated with hypercalcemia which likewise represents a property in human SCCOHT. Furthermore, re-culture of NOD/ scid mice-derived tumor cells were indistinguishable from the GFP-transduced primary SCCOHT-1 cells further supporting a stable phenotype derived from the original patient tumor.

Together, these findings suggested the successful isolation and characterization of a spontaneous permanently growing 
SCCOHT-derived cell population. This culture provides the first cellular model to further investigate this malignancy particularly with respect to cell biological properties and signaling pathways related to the paralleled hypercalcemia. Moreover, the reproducible generation of in vivo tumors in $\mathrm{NOD} / \mathrm{scid}$ mice may serve as an appropriately corresponding in vivo tumor model, which also for the first time enables a disease-focused drug screening to search and examine effective and sufficient therapeutic strategies for this rather unknown type of cancer.

\section{Acknowledgements}

The technical support by Marianne Thren is appreciated. The authors are grateful for the help of Dr Silke Glage (Hannover Medical School) with the calcium measurements. This study was supported by a grant from the Niedersächsische Krebsgesellschaft e.V. to R.H.

\section{References}

1. Dickersin GR, Kline IW and Scully RE: Small cell carcinoma of the ovary with hypercalcemia: a report of eleven cases. Cancer 49 : 188-197, 1982.

2. Young RH, Oliva E and Scully RE: Small cell carcinoma of the hypercalcemic type in the ovary. Gynecol Oncol 57: 7-8, 1995.

3. Scully RE: Atlas of tumor pathology: tumors of the ovary and maldeveloped gonads. Armed Forces Institute of Pathology, Washington DC, 1979.

4. Eichhorn JH and Young RH: Transitional cell carcinoma of the ovary: a morphologic study of 100 cases with emphasis on differential diagnosis. Am J Surg Pathol 28: 453-463, 2004.

5. Geisinger KR, Kute TE, Pettenati MJ, et al: Characterization of a human ovarian carcinoma cell line with estrogen and progesterone receptors. Cancer 63: 280-288, 1989.

6. Hamilton TC, Young RC, McKoy WM, et al: Characterization of a human ovarian carcinoma cell line (NIH:OVCAR-3) with androgen and estrogen receptors. Cancer Res 43: 5379-5389, 1983.

7. Poels LG, Jap PH, Ramaekers FF, et al: Characterization of a hormone-producing ovarian carcinoma cell line. Gynecol Oncol 32: 203-214, 1989.

8. Bible KC, Boerner SA, Kirkland K, et al: Characterization of an ovarian carcinoma cell line resistant to cisplatin and flavopiridol. Clin Cancer Res 6: 661-670, 2000.

9. Ohi S, Niimi S, Okada N, et al: Establishment and characterization of a human ovarian small cell carcinoma, hypercalcemic type, cell line (OS-1) secreting PTH, PthrP and ACTH--special reference to the susceptibility of anti-cancer drugs. Hum Cell 17: 203-209, 2004

10. Ulbright TM, Roth LM, Stehman FB, Talerman A and Senekjian EK: Poorly differentiated (small cell) carcinoma of the ovary in young women: evidence supporting a germ cell origin. Hum Pathol 18: 175-184, 1987.

11. Aguirre P, Thor AD and Scully RE: Ovarian small cell carcinoma Histogenetic considerations based on immunohistochemical and other findings. Am J Clin Pathol 92: 140-149, 1989.

12. Walt H, Hornung R, Fink D, et al: Hypercalcemic-type of small cell carcinoma of the ovary: characterization of a new tumor line. Anticancer Res 21: 3253-3259, 2001.

13. McCluggage WG, Oliva E, Connolly LE, McBride HA and Young RH: An immunohistochemical analysis of ovarian small cell carcinoma of hypercalcemic type. Int J Gynecol Pathol 23: 330-336, 2004.

14. Scully RE: Small cell carcinoma of hypercalcemic type. Int J Gynecol Pathol 12: 148-152, 1993.

15. Eichhorn JH, Bell DA, Young RH, et al: DNA content and proliferative activity in ovarian small cell carcinomas of the hypercalcemic type. Implications for diagnosis, prognosis, and histogenesis. Am J Clin Pathol 98: 579-586, 1992.

16. Shrimali RK, Correa PD and Reed NS: Dose-dense and doseintense chemotherapy for small cell ovarian cancer: 2 cases and review of literature. Med Oncol 28: 766-770, 2011.
17. Harrison ML, Hoskins P, du Bois A, et al: Small cell of the ovary, hypercalcemic type - analysis of combined experience and recommendation for management. A GCIG study. Gynecol Oncol 100: 233-238, 2006.

18. Benrubi GI, Pitel P and Lammert N: Small cell carcinoma of the ovary with hypercalcemia responsive to sequencing chemotherapy. South Med J 86: 247-248, 1993.

19. Reed WC: Small cell carcinoma of the ovary with hypercalcemia: report of a case of survival without recurrence 5 years after surgery and chemotherapy. Gynecol Oncol 56: 452-455, 1995.

20. Barondeau J, Rodgers M, Braun L, Azarow K, Forouhar M and Faucette K: Small cell ovarian carcinoma: a rare, aggressive tumor masquerading as constipation in a teenager with a fatal outcome. J Pediatr Hematol Oncol 32: e139-e141, 2010.

21. Dykgraaf RH, de Jong D, van Veen M, Ewing-Graham PC, Helmerhorst TJ and van der Burg ME: Clinical management of ovarian small-cell carcinoma of the hypercalcemic type: a proposal for conservative surgery in an advanced stage of disease. Int J Gynecol Cancer 19: 348-353, 2009.

22. Distelmaier F, Calaminus G, Harms D, et al: Ovarian small cell carcinoma of the hypercalcemic type in children and adolescents: a prognostically unfavorable but curable disease. Cancer 107: 2298-2306, 2006

23. Gebert A and Preiss G: A simple method for the acquisition of high-quality digital images from analog scanning electron microscopes. J Microsc 191: 297-302, 1998.

24. Bertram C and Hass R: Cellular senescence of human mammary epithelial cells (HMEC) is associated with an altered MMP-7/ HB-EGF signaling and increased formation of elastin-like structures. Mech Ageing Dev 130: 657-669, 2009.

25. Schlegelberger B, Metzke S, Harder S, Zühlke-Jenisch R, Zhang Y and Siebert R: Classical and Molecular Cytogenetics of Tumor Cells. Springer Verlag, Heidelberg, 1999.

26. Shaffer L, Slovak M and Champbell L: ISCN - An International System for Human Cytogenetic Nomenclature. S. Karger AG, Basel, 2009.

27. Gohring G, Hanke C, Kratz C, et al: Fluorescence in situ hybridization using the subtelomeric 11q probe as a diagnostic tool for congenital thrombocytopenia. Ann Hematol 85: 883-885, 2006.

28. Schambach A, Galla M, Modlich U, Will E, Chandra S, Reeves L, Colbert M, Williams DA, von Kalle C and Baum C: Lentiviral vectors pseudotyped with murine ecotropic envelope: increased biosafety and convenience in preclinical research. Exp Hematol 34: 588-592, 2006.

29. McCluggage WG, McKenna M and McBride HA: CD56 is a sensitive and diagnostically useful immunohistochemical marker of ovarian sex cord-stromal tumors. Int J Gynecol Pathol 26: 322-327, 2007.

30. Ohishi Y, Kaku T, Oya M, Kobayashi H, Wake N and Tsuneyoshi M: CD56 expression in ovarian granulosa cell tumors, and its diagnostic utility and pitfalls. Gynecol Oncol 107: 30-38, 2007.

31. Majore I, Moretti P, Hass R and Kasper C: Identification of subpopulations in mesenchymal stem cell-like cultures from human umbilical cord. Cell Commun Signal 7: 6, 2009.

32. Lavrentieva A, Majore I, Kasper C and Hass R: Effects of hypoxic culture conditions on umbilical cord-derived human mesenchymal stem cells. Cell Commun Signal 8: 18, 2010.

33. Pirozzi G, Tirion V, Camerlingo R, et al: Epithelial to mesenchymal transition by TGFbeta- 1 induction increases stemness characteristics in primary non small cell lung cancer cell line. PLoS One 6: e21548 2011.

34. Martinez-Borges AR, Petty JK, Hurt G, Stribling JT, Press JZ and Castellino SM: Familial small cell carcinoma of the ovary. Pediatr Blood Cancer 53: 1334-1336, 2009.

35. Denison SR, Callahan G, Becker NA, Phillips LA and Smith DI: Characterization of FRA6E and its potential role in autosomal recessive juvenile parkinsonism and ovarian cancer. Genes Chromosomes Cancer 38: 40-52, 2003.

36. Kamal M, Shaaban AM, Zhang L, et al: Loss of CSMD1 expression is associated with high tumour grade and poor survival in invasive ductal breast carcinoma. Breast Cancer Res Treat 121: 555-563, 2010.

37. Park SY, Kwon HJ, Lee HE, et al: Promoter CpG island hypermethylation during breast cancer progression. Virchows Arch 458: 73-84, 2011.

38. Turnbull C, Rapley EA, Seal S, et al: Variants near DMRT1, TERT and ATF7IP are associated with testicular germ cell cancer. Nat Genet 42: 604-607, 2010. 